\title{
THE “PSYCHOSOMATIC FAMILY” RECONSIDERED II: RECALLING A DEFECTIVE MODEL AND LOOKING AHEAD
}

\author{
James C. Coyne \\ University of Michigan \\ Medical School
}

\author{
Barbara J. Anderson \\ Joslin Diabetes Center \\ Boston, MA
}

\begin{abstract}
The notion of the "psychosomatic" family continues to enjoy uncritical acceptance in the absence of promised data and despite its dependence on an outmoded view of how psychosocial factors are involved in illness. We review the decline of psychosomatic models of illness that assume that arousal is the only or primary means by which psychosocial factors influence illness. Focusing on brittle diabetes, we note the potential for family theorists to develop more adequate models of poor self-care and medical crises as interactional tactics, as dynamic efforts to solve problems, define relationships, and influence others, even if they are costly and self-defeating. In an appendix, we note the inadequacy of Rosman and Baker's (1988) reanalyses of the Minuchin, Rosman and Baker (1978) data.
\end{abstract}

Like many researchers and clinicians, we read Psychosomatic Families (Minuchin et al., 1978) with great enthusiasm when it first appeared. We recognized that the data presented in the book were preliminary and inconclusive, and that they were not provided in a form that allowed independent judgment about how best to interpret them. Yet, despite some reservations, we accepted the promissory note that the book seemed to offer, and eagerly waited for the full report of the studies of the familial context of poorly controlled diabetes. As Minuchin et al. (1978) assured us at the time, "This report is being prepared for publication" (p. 342).

A decade later, the promised report had not yet been published, and as we conducted research and therapy with the families of diabetic children, we were impressed with both the limits of the formulation of the family's role in diabetes offered in Psychosomatic Families and the uncritical acceptance that the book continued to enjoy. Family therapists potentially have much to contribute in any comprehensive approach to the treatment of chronic illness, but we were dismayed by the number of therapists whose model of the role of the family in chronic illness was limited to what they had read in Psychosomatic Families. We gave the text a renewed look. The resulting review (Coyne \& Anderson, 1988) had two aims:

1. To re-open discussion of a book that has been widely accepted as a convincing demonstration of a particular kind of link between family functioning and problems in the management of diabetes and, more generally, between family interaction and individual physiology. We hoped to stimulate family therapists to read it and reflect upon it critically with the vantage of the decade that has passed since its publication.

James C. Coyne, PhD, is Associate Professor, Departments of Family Practice and Psychiatry, University of Michigan Medical School, 1018 Fuller Street, Box 0708, Ann Arbor, MI 48109.

Barbara J. Anderson, PhD, is a Psychologist, Mental Health Unit, Joslin Diabetes Center, Boston, MA 02215. 
2. To remind the Philadelphia Child Guidance Clinic group of their promise to provide a more complete presentation of the data of which they had given only tantalizing glimpses in the original book. Neither methods nor data were presented in a way that met customary standards for scientific communication. We had hoped that the Philadelphia Child Guidance Clinic group might now present the study in a way that independent evaluation was possible.

Hopefully, our review and the reply by Rosman and Baker (1988) will serve to encourage family therapists to broaden their reading and thinking about diabetes. Readers with some statistical background will be aware that Rosman and Baker did not provide an adequate analysis of their data. Correlational analyses utilizing difference scores and a sample size of 7 cannot possibly demonstrate the "crossover effect" Rosman and Baker claim. In an Appendix to this article, we provide a more detailed discussion of statistical issues for the interested reader and renew our request for the data that had been promised but not delivered.

Rosman and Baker also presented a spirited defense of what is now an outdated view of the illness and its treatment. Minuchin et al. (1978) had noted that their results were limited to families with "psychosomatic diabetes," and that it was only in this group that they claimed support for their hypothesis of psychosomatic disease. Yet, they claimed that therapeutic observation with families of patients suffering from other ilnesses had validated the generalizability of their results (cf. p. 49), and it is this more sweeping claim that has obtained the greatest attention. We believe that it is time that the field reconsider the adequacy of the concept of a "psychosomatic" diabetic child, particularly as it lends credibility to a more general conception of a "psychosomatic family." There are important theoretical implications of such a conception, but we should not miss the practical ones. The notion of a "psychosomatic family" can lead a family therapist to miss obvious opportunities to assist families in the throes of medical crises to change their behavior, related to diabetes and its treatment at home. Given these concerns, we will go beyond the exchange with Rosman and Baker (1988) and focus our discussion on this outdated concept and begin to suggest what a replacement model would look like.

\section{THE RISE AND FALL OF PSYCHOSOMATIC CONCEPTS}

The notion of "psychosomatic" diabetes is not generally accepted in the diabetes literature. One can search in vain for a discussion of it in standard textbooks. If the term occurs at all, it is typically in quotation marks and limited to discussions of the work of the Philadephia group.

In designating some diabetic patients as "psychosomatic," Minuchin et al. were drawing upon a conception of how psychosocial factors are involved in physical illness, that had earlier beeen in vogue, but that had already been rejected by the time the book appeared. The basic notion was that sustained emotional upset caused physical illness (Alexander, 1950). In the case of diabetes, this idea can be traced as far back as Willis (1679, cited in Surwit, Feinglos \& Scovern, 1983). In the early 20th century, psychosomatic theory became wedded to the psychoanalytic movement, and speculation was focused on how global personality traits might predispose a person to react to stress with a somatic response. Minuchin et al. (1978), thus, borrowed a conceptual strategy from psychosomatic medicine and took it to a higher level of organization - the familypreserving its basic form.

By the late '60s, psychosomatic medicine had fallen into disfavor. As Suls and Rittenhouse (1987) have noted, the notion of psychosomatic disorders was found to have too little explanatory and predictive power. While ostensively explaining how arousal might contribute to physical illness, psychosomatic concepts failed to explain why only
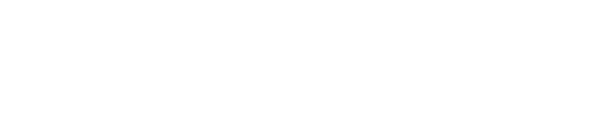
some persons became ill or why illness should take a particular form. People can be aroused without becoming ill, and arousal does not necessarily exacerbate the condition of persons already ill. The psychosomatic model also failed to explain how psychological states might translate into the endocrine abnormalities. The very plausibility of psychological states translating directly into such abnormalities generally depended upon ignorance of identifiable biological pathways. In disease after disease, as more was learned about biological processes, psychosomatic explanations declined in influence (Dakof \& Mendelsohn, 1986). One review, specifically focusing on diabetes, noted, "the psychosomatic approach has not been found to be of any practical utility in helping patients and physicians manage the disease ... Clearly, if psychology is to make a meaningful contribution to the understanding and treatment of diabetes, a new approach is necessary" (Surwit, Feinglos \& Scovern, 1983, p. 256).

The decline of the influence of psychosomatic concepts was apparent in many ways, including the deletion of psychosomatic conditions from the DSM-III (American Psychiatric Association, 1980). Beyond that, accumulated scepticism about the notion of psychosomatic disorders had, by the mid-sixties, led to a premature, but widespread rejection of any role for psychosocial factors in health (Holroyd \& Coyne, 1987). It was only with the advent of research concerning stressful life events that the credibility of this idea was reestablished, and one can find ample evidence that a credibility gap still exists, as in a recent editorial in the New England Journal of Medicine (Angell, 1985).

The notion that psychosocial factors, and particularly stress, should influence health has been revived in health psychology and behavioral medicine. However, many theorists, clinicians, and researchers now explicitly reject the notion of psychosomatic illness as overly simplistic and as placing too much emphasis on unverifiable psychogenic factors. Further, it is no longer assumed that generalized arousal is the only or primary means by which stress influences health (Coyne \& Holroyd, 1982; Holroyd \& Coyne, 1987). Hypotheses about the role of arousal in susceptibility to illness are more circumscribed and specific, as can be seen in the evolving work examining the association between cynical hostility and cardiovascular disease (Demboski \& Costa, 1987). Overall, the emerging health psychology or biopsychosocial paradigm is a broad one without firm boundaries. It does not assume that causal links have to be established in order to make psychosocial factors relevant to managing medical conditions, and, therefore, the paradigm is not limited to disorders defined as psychophysiological or what used to be termed "psychosomatic." Certainly, one does not have to "rule out" organic factors to claim a relevance. Generally, one cannot so easily dismiss such factors. Further, diabetes does not have to be "psychosomatic" for psychosocial factors to be crucial in its management.

Sadly, family therapists have not had much of a role in these developments, and the family gets very little attention in health psychology (Dakof, 1987). As an example, one massive text (Stone, Cohen \& Adler, 1979) contained only a single entry for the family in its index, and that is only for a self-report family assessment inventory. Antiquated concepts like the "psychosomatic family" do not serve to encourage a rapprochement. The continued use of this notion by family therapists suggests that they are ill-informed and still holding onto a narrow arousal-based conception of how psychosocial factors are involved in physical illness that has already been discarded as inadequate.

\section{“PSYCHOSOMATIC" DIABETES}

Rosman and Baker (1988) state that their work encompasses a group of diabetic children with repeated DKA, for whom "alternative explanations of poor diabetic management or organic causes have been rigorously ruled out" (p. 126). Since the work 
reported in Minuchin et al. (1978) was completed, there have been considerable advances in the tools for managing diabetes and in assessing the bases of poor control. Yet, even now, ruling out organic factors and poor diabetic management is not as clear-cut as Rosman and Baker suggest. A decade after this work, Keen (1985) has stated, "It is not easy to devise a diagnostic schema which could be systematically applied to separate 'organic,' explicable cases from the putative 'psychic' or behavioural cases" (p. 6).

Moreover, careful work, focusing on understanding more about very labile diabetes in adults (Schade, Drumm, Duckworth \& Eaton, 1985; Williams, Pickup \& Keen, 1985) and in children (Golden, Herrold \& Orr, 1985; White, Kolman, Wexler, Polin \& Winter, 1984), has been conducted since the publication of Psychosomatic Families. In 1989 , we have the benefit of putting the "relative rarity of the true psychosomatic disorder" (Rosman \& Baker, 1988, p. 126) in a new, and much broader, perspective.

While each of the above studies has documented the existence of stressful personal and family circumstances in the majority of individuals with very labile diabetes, these investigations have also pointed to the contributions of the patient's behavior to this metabolic instability, i.e., to the manipulation of diabetes-related self-care behavior as a tactic for coping with stressful life circumstances. As Rizza, Zimmerman \& Service, (1985) summarize:

Careful attention must be paid to behavioral aspects of the remaining subset with alleged brittle diabetes. It is essential to recognize noncompliance or malingering when it is the basis for brittle diabetes to direct efforts to the correction of the aberrant behavior and avoid embarking on complex and potentially risky treatment techniques such as chronic venous or intraperitoneal insulin delivery, which, in these cases, would be assured of failure. (p. 95)

A model in which arousal is seen as the mechanism causing or mediating repeated episodes of DKA distracts family therapists from probing the self-care behavior issues which have been documented over and over again to occur in concert with family and school-related stresses in children with repeated episodes of DKA. Further, an insistence on the necessity of changing the basic family structure thwarts a real investigation of the role of self-care behavior in metabolic instability. For example, White et al. (1984) describe depression, anxiety and poor self-esteem in children with repeated DKA, but admit that they "could not establish to what degree these emotional problems were related to their diabetes, their unsatisfactory home situation, or some other factor. However, these feelings did influence how the children care for themselves and their health" (p. 753). It is no simple task to "rule out management problems" (Rosman \& Baker, 1988, p. 126), and one need only to read Schade et al.'s (1985) account of the exquisite scrutiny needed to uncover the maladaptive self-care behavior in some patients with IDDM to appreciate how many resources and how much time must be devoted, in some cases, to understanding self-care behavior as interactional tactics.

Rosman and Baker (1988) identify one of the most significant problems with the "psychosomatic diabetic" model early in their reply to our review: "Perhaps what is not well understood is the relative rarity of the true psychosomatic disorder" (p. 126). This is emphasized again on the last page: "Our model ... was limited to a specific and welldefined population. If some have erroneously applied the model in a global way to the wrong patients, we will criticize them ..." (p. 131). 'This emphasis on the rarity of the condition is indeed new. The Philadelphia Child Guidance Clinic group has itself encouraged such "global" applications of their model. For example, one member of this group (Sargent, 1985) has recently reported:

“The goals of family therapy for psychosocial difficulties in diabetes management are to 1) create new family structures that will promote effective medical treatment, 2) reduce the family stress that induces physical symptoms, 3) decrease the role of physical symp- 
toms in maintaining family stability and 4) assist the family in encouraging appropriate autonomy and development of all members, especially the diabetic child" (p. 228).

Would family therapists who follow this advice and concentrate on reducing "the family stress that induces physical symptoms" in families with "psychosocial difficulties," and who, therefore, may have missed other important behavioral issues related to diabetes self-care, fall under the "criticism" which Rosman and Baker (1988) promise for those who apply "the model in a global way to the wrong patients" (p. 131)? Sargent (1985) discusses "reduction of family stress that induces physical symptoms" as a goal for family therapy without any caveat about the rarity of "psychosomatic" diabetes. Further, a discussion of a specific case (p. 219) draws a connection between parental discord and the child's ketoacidosis, but leaves the nature of the connection mysterious. Like Rosman and Baker (1988) and Minuchin et al. (1978), Sargent ignores the wellestablished role of inadequate self-care as an interactional tactic in poorly controlled diabetes.

\section{BRITTLE DIABETES AND THE POTENTIAL CONTRIBUTION OF FAMILY THERAPISTS}

There has been continuing progress in the medical management of IDDM. Before the 1920s, most patients with IDDM died within 2-3 years as a result of severe metabolic decompensation (Haycock, 1983). With the introduction of insulin therapy in the early twenties, such metabolic decompensation became the exception, and the lives of patients with IDDM could be prolonged. By the 1980 s, tools such as self-monitoring of blood glucose levels, multiple daily insulin injections, and even continuous infusion insulin pump therapy insured that increasing numbers of IDDM patients are able to maintain near-normal blood sugar levels much of the time. It should be emphasized that although the management of diabetes remains challenging, most diabetic children and adolescents do not now display a disruptive medical course. Indeed, there is much to be learned about how so many patients and their families adapt as well as they do.

Yet, there are identifiable patients who experience a cycle of dysfunction, with closely linked medical and interpersonal crises. The term "brittle diabetes" has been applied to those few patients who exhibit such severe fluctuations in metabolic control that they are unable to maintain a relatively normal lifestyle (Tattersall, 1977; White \& Santiago, 1985). Unlike "psychosomatic" diabetes, this term is widely accepted and meant to be purely descriptive. It is deliberately noncommittal on the question of etiology. Appropriately, it does not involve assumptions that the same etiological factors operate across cases or that a single etiological factor can explain a particular case. Precise definitions of brittle diabetes vary somewhat, and as a result, estimates of its prevalence vary. White \& Santiago (1985) applied the term to $5 \%$ of their young patients with IDDM. Apparently using much stricter criteria, Keen (1985) estimated that there were only 20 to 30 such patients in the United Kingdom at any one time.

As White and Santiago (1985), Keen (1985), Pickup, Home, Bilous, Keen \& Alberti, (1981) and others characterize their patients with brittle diabetes, they are overwhelmingly female and adolescents or young adults. There is a close association between the onset of brittle diabetes and puberty, among both patients who developed diabetes earlier in childhood and those who developed it near puberty (White \& Santiago, 1985). There are frequently pre-existing family and other psychosocial factors in the lives of these patients: economic hardships, single parent homes or overt marital turmoil, overdependent relationships, chronic physical illness and psychiatric problems in parents, and inability to involve the parents in diabetes care. Yet, as Keen (1985) points out, these same problems occur in the backgrounds of many stable diabetic patients. 
Various biomedical causes of brittle diabetes have been identified, including problems with insulin absorption, antibody response to insulin, counter-regulatory hormone effects, and the Somogyi phenomenon-a paradoxical reaction to extremely low blood sugars. Tattersall and Walford (1985) have suggested that the patient's behavior is a major influence in most cases of brittle diabetes. It is important for family therapists to appreciate that biomedical and behavioral causes of brittle diabetes are not mutually exclusive, and each may contribute to the evolution of the other. The identification of a clear biomedical problem in a particular case does not eliminate the need to examine the relevance of both the family context and the patient's self-care behavior. A patient whose first serious bouts of hyperglycemia may be the result of incorrect insulin dosage, illness, or faulty insulin absorption may discover how devastating a weapon such a lifethreatening crisis can be within the family. Further, a patient may deliberately create initial metabolic crises, which, in turn, take on a life of their own:

Escalation of insulin doses, continued cheating and repeated admissions could then create a chain of events leading to a state of chronic hyperglycemic instability ... The instability may now be thought of as an "acquired metabolic" problem, though cheating may still play a part in some patients at this stage" (Gill, Husband, Walford, Walford, Marshall, Home \& Alberti, 1985. p. 38).

Patients can be quite creative in their noncompliant and manipulative behavior, and it may take considerable work to detect this, even in a controlled hospital setting. Schade et al. (1985) have reported patients injecting insulin surreptitiously to produce hypoglycemic seizures, replacing insulin with water, and crimping catheters to cut off the flow of intravenous insulin. Medical personnel may have a vague sense that the interactional context is relevant to such behavior, just as they are aware that the family may be relevant. Yet, what is missing and crucially needed is a framework for understanding the dynamics by which such behavior and the associated medical crises can shape relationships and vice versa. Family therapists, thus, have the opportunity to develop a framework for explaining how behaviors related to brittle diabetes can evolve in a family context, how that context co-evolves with the patient's behavior, and how the behavior of the patient and the rest of the family become mutually maintaining. The crucial shift, however, is to viewing self-care behavior and the resulting crises as interpersonal tactics, as dynamic efforts to solve problems, define relationships, and influence others, even if they are costly and self-defeating. This view must be contextualized in terms of how others-notably other family members and even medical staffare trying to solve the problems as they see them and exert an influence on the unfolding events. The psychosomatic family model is unlikely to be of much help, and its misplaced and overstated emphasis on arousal is a distraction from these tasks.

Further, family therapists have the opportunity to develop ways of intervening to insulate diabetes management and the metabolic stability of the diabetic patient from intractable family conditions. The same family conditions that are tied to brittle diabetes are likely to be associated with a failure to accept or benefit from conventional family therapy. Most families with a diabetic child who has repeated medical emergencies will reject participation in therapy (Golden, Herrold \& Orr, 1985), much less therapy aimed at a fundamental reorganization of family structure. Yet, even when intervention is not formally defined as therapy, family therapists can potentially provide valuable consultation as to how to deal with issues of autonomy and control, and they can encourage an appreciation of the interactional significance of both compliance and noncompliance. Faced with the life-threatening crises of diabetes, medical personnel and family members alike often fail to appreciate the interpersonal dynamics or problem-maintaining solutions in which they have been caught up. 
In summary, family therapists need a broader-based model if they are to provide an adequate understanding of the role of the family in brittle diabetes and other chronic illness. In the case of diabetes, such a model would give attention to: (a) individual differences in the difficulty in achieving adequate metabolic control, particularly biomedical factors; (b) the possibility of control problems as tactics in relationships; (c) the family as an open system influenced by how it is engaged by the medical system; and (d) the problems of achieving metabolic control in chaotic and otherwise dysfunctional families, the effects of poor control on families, and how these effects unfold over time. The first step is to focus on observable sequences, not elusive links between arousal and metabolism. The recognition that family stress and metabolic control problems co-occur should be the starting point for developing an understanding of a particular case, not the conclusion.

\section{APPENDIX: THE GAP BETWEEN PROMISE AND DATA}

Minuchin et al (1978) claimed to have demonstrated a direct link between observed family patterns and individual physiology such that the functional significance of the poorly controlled diabetes for the family had been established. To our knowledge, none of the observational data have ever been revealed in print. Coyne and Anderson (1988) detailed some of the problems of the original presentation of the physiological (free fatty acid; FFA) data in Psychosomatic Families. Given the reliance on analyses that do not preserve the family as the unit of analysis to argue about family dynamics, and the absence of basic descriptive statistics or significance tests, one certainly could doubt as to whether the data offered any support at all for the interpretations that the authors provided. Rosman and Baker (1988) acknowledge, "It is true that the original presentation of the data here was not in standard form ..." (p. 128). The issue is not whether Minuchin et al.'s presentation of their data was "standard form," but whether their data in any way supported their claim that they had a "scientific confirmation" of their hypotheses.

Rosman and Baker's new analyses (1988) have not alleviated this problem. Although they renewed the claim of Minuchin et al. (1978) that the function of the patients' symptoms in their families had been demonstrated, yet, at best, the new analyses offer limited evidence that the patients with "psychosomatic" diabetes were more upset, as measured by FFA levels. One could have predicted that from the nature of the crises that these patients faced. One might even anticipate that their parents also had elevated FFA levels.

Regardless, by the usual standards of evidence, no support is offered for the view that the symptoms of the diabetic patients served a function in their families. As with Minuchin et al. (1978), the issue is not one of being picky or of disagreeing on a minor technical point, but of there being a major departure from how data are treated and interpreted in refereed journals. It appears that claims of neither Rosman and Baker (1988) nor Minuchin et al. (1978) are derived from what is available in the data.

It would be useful to note what analyses would be appropriate and why the new analyses shed so little light on what happened in the original study. The study involved three small groups of families, each of which consisted of a child, a father, and a mother who were observed under four conditions. Appropriate analyses should make as full a use of this design as possible, preserving both the relatedness of family members (i.e., the family as the unit of analysis) and the fact that it was the same families being observed across the four conditions. Ideally, this would be accomplished using a $3 \times 3$ $\times 4$ repeated-measure ANOVA with group (normal, behavioral-problem, or "psychosomatic" diabetic patient) as one factor, and family member (child, father, mother) and observation period $(1,2,3$, or 4$)$ as the repeated factors. Most of the interesting and
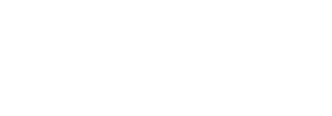
relevant analyses would focus on interactions among these factors. However, such analyses would require statistical power to the extent that such a small sample is unlikely to afford. Particularly with highly variable physiologieal data, it is unlikely that this small size would provide rejection of the null hypothesis that anticipated differences do not occur.

Instead of ANOVA, Rosman and Baker utilized the Mann-Whitney test in multiple efforts to uncover differences among the patients at single points in time. It is a nonparametric test that examines whether two distributions are different, not whether means (or other central tendencies such as mode or median) of two samples are different. This choice of analysis is unfortunate because it suppresses information and can yield only ambiguous results. Particularly with such a small sample, one simply does not have a basis for concluding from a significant Mann-Whitney $U$ that the FFA levels of one group are significantly different from another. Even with a larger number of subjects, two samples could have the same mean or modal FFA values and still yield a significant value for $U$ because of differences in the distribution of the FFA values. Thus, statistically significant results are not necessarily enlightening about whether hypothesized differences occur. Again, even if we grant that the groups of patients tended to be different, it is not clear what support this offers for the strong claims of Minuchin et al. (1978) and Rosman and Baker.

The use of the Mann-Whitney test is understandable even if unsatisfactory, but Rosman and Baker's correlational analyses are more puzzling. First, recall that each family had two parents and a child present for the experimental task, thus yielding three data points at any single observation. Yet, a correlation coefficent is bivariate in nature, and so one parent apparently got dropped from each family, or the data from the two parents were somehow combined. In their original presentation of their data, Minuchin et al. simply dropped the parent in each family who had the lower FFA value (1978, p. 46). Perhaps Rosman and Baker did the same. More than being nonstandard, this capitalizes on chance and does not produce an interpretable statistic. Subsequent statements about significance become meaningless.

Second the correlation coefficent is based on a sample size of 7 . This is problematic because this statistic is so susceptible to sample fluctuation and outliers with such a small sample. The reader can get a sense of this by arbitrarily graphing a scatterplot of 7 data points and observing the effects of eliminating or moving any one of them on the regression line that best fits the set of them. Generally speaking, one does not attempt correlational analyses with such a small sample size. One cannot even adequately determine whether the required assumptions for a test of significance are being met.

A third, and even more serious, difficulty is posed by Rosman and Baker's reliance on change scores. Tackling the issue of how, or even whether, change in a child's FFA levels is related to changes in parent FFA values requires multiple regression or related techniques, which, in turn, require a much larger sample. A standard text, Cohen and Cohen (1975), has shown how an approach to correlation such as taken by Rosman and Baker (1988) results in a spuriously inflated and otherwise uninterpretable correlation coefficent. Cohen and Cohen (1975) go on to show how the kind of results obtained by Rosman and Baker are best understood as a failure to control the effects of initial differences: Any significant correlation using change scores is likely to be an artifact of initial differences in patients' or parents' FFA levels, not a crossover effect. Again, the issue is not one of being picky, but of a serious departure from the ways in which data are typically utilized, analyzed and interpreted.

A decade after the publication of Psychosomatic Families, we ask, where are the data? Minuchin et al.'s (1978) provocative ideas about how families are involved in chronic illness have been given a unique status in the field because of the promise that they would be substantiated with data showing the role that some "psychosomatic" 
diabetic children play in their families. Without actually being available for scrutiny, these same data have been widely cited as a compelling demonstration that symptoms serve functions in families. However, the basis for these claims still has not been forthcoming, and Rosman and Baker's (1988) only weakens their claims that their model is data-based. In defending their original work, they infelicitiously adopted the metaphor of parents for themselves. Given their rejection of another opportunity to give an adequate presentation of the data and given the manner in which they defend a 10 year-old model, we feel like we are responding to used-car dealers who insist an old car is as good as new, but won't let us look under the hood. Caveat emptor.

\section{REFERENCES}

Alexander, F. (1950). Psychosomatic medicine: Its principles and applications. New York: Norton. American Psychiatric Association. (1980). Diagnostic and statistical manual of mental disorders. Third edition. Washington, D.C: Author.

Angell, M. (1985). Disease as a reflection of the psyche. New England Journal of Medicine, 312, $1570-72$.

Cohen, J. \& Cohen, P. (1975). Multiple regression analysis for the behavioral sciences, Hillsdale, NJ: Lawrence Erlbaum Associates.

Coyne, J. C. \& Anderson, B. J. (1988). The "psychosomatic family" reconsidered: Diabetes in context. Journal of Marital and Family Therapy, 14, 113-123.

Coyne, J. C. \& Holroyd, K. (1982). Stress, coping, and illness: A transactional perspective. In T. Millon, C. Green \& R. Meager (Eds.), Handbook of health care clinical psychology. New York: Plenum.

Dakof, G. A. (1987), At the starting gate: Research and theory on families and somatic health. Journal of Family Psychology, 1, 135-141.

Dakof, G. A. \& Mendelsohn, G. A. (1986). Parkinson's disease: The psychological aspects of a chronic illness. Psychological Bulletin, 99, 375-387.

Demboski, T. M. \& Costa, P. T. (1987). Coronary prone behavior: Components of the Type A pattern and hostility. Journal of Personality, 55, 211-235.

Gill, G. V., Husband, D. J., Wilford, S., Walford, S., Marshall, S. M., Home, P. D. \& Alberti, G. M. M. (1985). Clinical features of brittle diabetes. In J. C. Pickup (Ed.), Brittle diabetes. St. Louis: Blackwell Scientific Publications.

Golden, M. P., Herrold, A. J. \& Orr, D. P. (1985). An approach to prevention of recurrent diabetic ketoacidosis in the pediatric population. Journal of Pediatrics, 107, 195-200.

Haycock, P. (1983). History of insulin therapy. In S. S. Schade, J. V. Santiago, J. S. Skyler \& R. A. Rizza (Eds.), Intensive insulin therapy. Princeton: Excerpta Medica.

Holroyd, K. \& Coyne, J. C. (1987). Personality and health in the 1980s: Psychosomatic medicine revisited? Journal of Personality, 55, 359-375.

Keen, H. (1985). Of mind and metabolism: An overview of brittle diabetes. In J. C. Pickup (Ed.), Brittle diabetes. St. Louis: Blackwell Scientific Publications.

Minuchin, S., Rosman, B. L. \& Baker, L. (1978). Psychosomatic families: Anorexia nervosa in context. Cambridge, MA: Harvard University Press.

Pickup, J. C., Home, P. D., Bilous, R. W., Keen, H. \& Alberti, K. G. M. M. (1981). Management of severely brittle diabetes by continuous subcutaneous and intramuscular insulin infusion: Evidence for a defect in subcutaneous insulin absorption. British Medical Journal, 282, 34750.

Rizza, R. A., Zimmerman, B. R. \& Service, F. J. (1985). Brittle diabetes. Diabetes Care, 8, 93-96.

Rosman, B. L. \& Baker, L. (1988). The "psychosomatic family" reconsidered; Diabetes in Contexta reply. Journal of Marital and Family Therapy, 14, 125-132.

Sargent, J. (1985). Juvenile diabetes mellitus and the family. In P. I. Ahmed \& N. Ahmed (Eds.), Coping with juvenile diabetes. Springfield, IL.: Charles Thomas.

Schade, D. S., Drumm, D. A., Duckworth, W. P.\& Eaton, R. P. (1985). The etiology of incapacitating, brittle diabetes, Diabetes Care, $8,12-20$. 
Stone, G., Cohen, F. \& Adler, N. (Eds.). (1979). Health psychology: A handbook. San Francisco: Jossey-Bass.

Suls, J. \& Rittenhouse, J. D. (1987). Personality and physical health: An introduction. Journal of Personality, 55, 155-167.

Surwit, R., Feinglos, M. N. \& Scovern, A. W. (1983). Diabetes and behavior: A paradigm for health psychology. American Psychologist, 38, 255-263.

Tattersall, R. (1977). Brittle diabetes. Clinical Endocrinology and Metabolism, 6, 403-19.

Tattersall, R. \& Walford, S. (1985). Brittle diabetes in response to life stress: "Cheating and Manipulation." In J. C. Pickup (Ed.), Brittle diabetes. St. Louis: Blackwell Scientific Publications.

White, K., Kolman, M. L., Wex]er, P., Polin, G. \& Winter, R. J. (1984). Unstable diabetes and unstable families: A psychosocial evaluation of diabetic children with recurrent ketoacidosis. Pediatrics, 73, 749-755.

White, N. H. \& Santiago, J. V. (1985). Clinical features and natural history of brittle diabetes in children. In J. C. Pickup (Ed.), Brittle diabetes. St. Louis: Blackwell Scientific Publications.

Williams, G., Pickup, J. C. \& Keen, H. (1985). Continuous intravenous insulin infusion in the management of brittle diabetes: Etiologic and therapeutic implications. Diabetes Care, 8, 2127.

\section{NOTE}

${ }^{1}$ Rosman and Baker (1988) assert that they were "very clear about the characteristics of patients studied" (p. 130), but neither they nor Minuchin et al. (1978) present basic descriptive data, such as the age-sex incidence of "psychosomatic" diabetes, that one would need to begin to interpret their claims. 